\title{
DISTRIBUTION RELIABILITY OF THE ENERGY SUPPLY CHAIN
}

\author{
Rachmad Hidayat ${ }^{1}$, Sabarudin Akhmad ${ }^{2}$ \\ ${ }^{1,2}$ Industrial Engineering Department, University of Trunojoyo Madura, Indonesia \\ E-mail: rachmad.trunojoyo@gmail.com
}

\begin{abstract}
Reliability of an oil fuel distribution system can be achieved by considering multiple attributes. Load-point indicators consisted of the frequency of failures, average duration of an outage and average annual outage time. Indicators of system performance were SAIFI and SAIDI and the method of the study was the Learning Vector Quantization (LVQ). Decisions were made by considering the multi-attribute oil fuel distribution system to determine high reliability, which was simulated on the agent. The use of agents in the simulation to determine the oil fuel distribution system reliability helped visualize the oil fuel distribution in meeting the quality of fuels received by consumers and made it easier to learn the problems faced by oil fuel distribution.
\end{abstract}

Keywords: oil fuel distribution, LVQ, agent, reliability

\section{INTRODUCTION}

Rising world oil prices have tremendous impacts on Indonesia's economy. The burden of oil fuel subsidy borne by the government is becoming increasingly high. This is compounded by the suboptimal fuel distribution system. The risk of distribution fraud is very likely to occur at the level of distributor or retailer. Among those forms of fraud are misallocation of oil fuels, sales of oil fuels for households or individuals to industries and smuggling of subsidized oil fuels abroad. (Ardiansyah, et.al., 2012). Oil fuels constitute a necessity which concerns the lives of many people. Oil fuel distribution requires transparency, necessitating public disclosure of distribution data as a form of the operator's accountability. A breakthrough should be found for smooth, transparent and traceable process of oil fuel distribution. The process of oil fuel distribution starts from the supply to the end user, the oil fuel consumers. The quality of oil fuels received by consumers is influenced the distribution system; therefore, a reliable oil fuel distribution system is required. Reliability of fuel distribution system is measured by the oil fuel availability and service level from the system to the end-users. (Simões, et. al., 2011). The benchmark of distribution system reliability includes how often the distribution system experiences a delay, how long a delay occurs and how quickly is the distribution system to recover to its previous normal condition. (Portugal and Esteban, 2014). A highly reliable system will be able to distribute oil fuels any time as needed, while a system is said to be poorly reliable when it provides a low level of oil fuel availability.

A highly reliable distribution system is indicated by the load points and system performance, consisting of the frequency of failures $(\lambda)$, average duration of a failure $(r)$, average annual outage time $(U)$. (González et. al., 2009). Based on these indications, multiple attributes can be considered to achieve a highly reliable distribution system, such as the load points, SAIFI and SAIDI. Subsequently, the multiple attributes are subjected to learning by the use of Learning Vector Quantization (LVQ) in order to automatically classify the given input vectors. Among the advantages of LVQ is the method's ability to provide learning to the competitive layers so that it can automatically classify the given input vectors (Fujiki and Kazuko, 2009).

The process for determining a highly reliable oil fuel distribution system is further simulated on an agent. An agent can help determine a highly reliable oil fuel distribution system with by considering multiple attributes. An agent is a component or individual capable of responding to the environment by considering many attributes and of adaptation so that they can make independent decisions. Reliability is defined as the ability of a component or system to perform the functions required in a particular environment and operational condition for a predetermined period of time (Ahmad and Kamaruddin, 2012). Thus, reliability constitutes one of the aspects capable of affecting the success of production process. Reliability is of paramount importance since it will affect the cost of maintenance, which in turn will affect the profitability of the company.

Reliability of the distribution system is a measure of oil fuel availability or service level of oil fuel provision from the system to the end-users. The measure of reliability can be expressed as how often the distribution system experiences a delay, how long a delay occurs and how quickly is the distribution system to recover to its previous normal condition. A highly reliable system will be able to provide oil fuel any time when needed, while a poorly reliable system is frequently late to distribute oil fuel. The service continuity level of the means of distribution is structured on the basis of length of the efforts to reestablish the supply after a downtime due to interruptions (Dhillon, 2005; González et. al, 2009).

Oil fuel distribution is part of the Energy Supply Chain, since the quality levels of oil fuels distributed from the refinery to the consumer are determined by the distribution system, particularly the reliability of the oil fuel distribution system. Distribution of oil fuels is influenced by multiple aspects, including minimizing losses, minimizing cost, improving reliability of supply, and satisfying operational constraints (Dhillon, 2005). Attribute planning for determining the reliability of an oil fuel distribution system is based on the load point indeices consisting of $\lambda, r$ and $U$ and the system performance index consisting of SAIFI and SAIDI can be seen in Figure 1. 


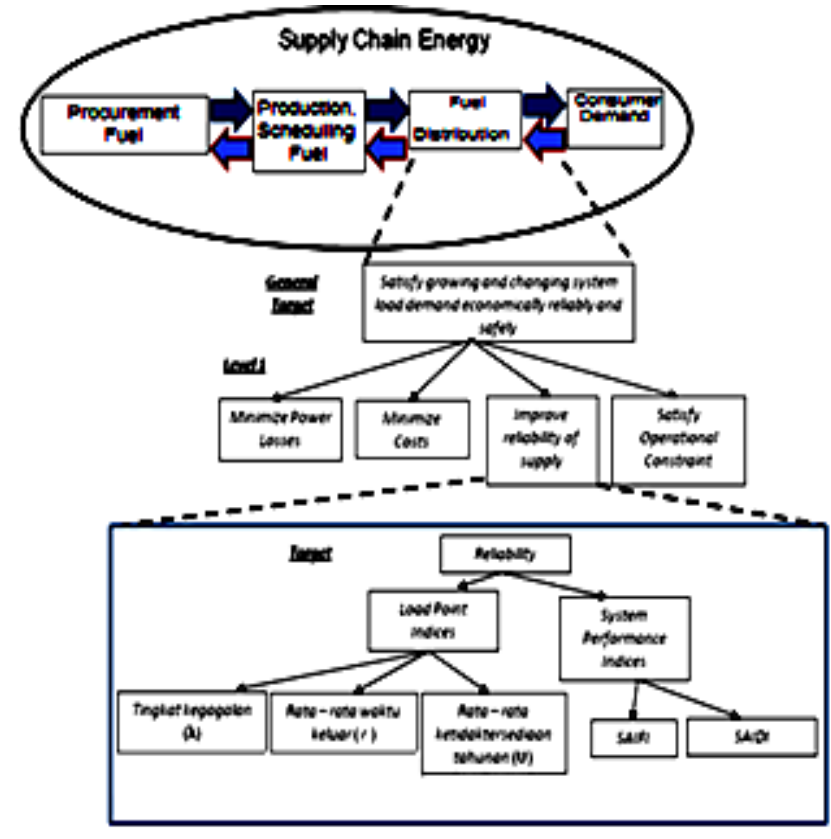

Figure-1. Oil fuel distribution in the Energy Supply Chain

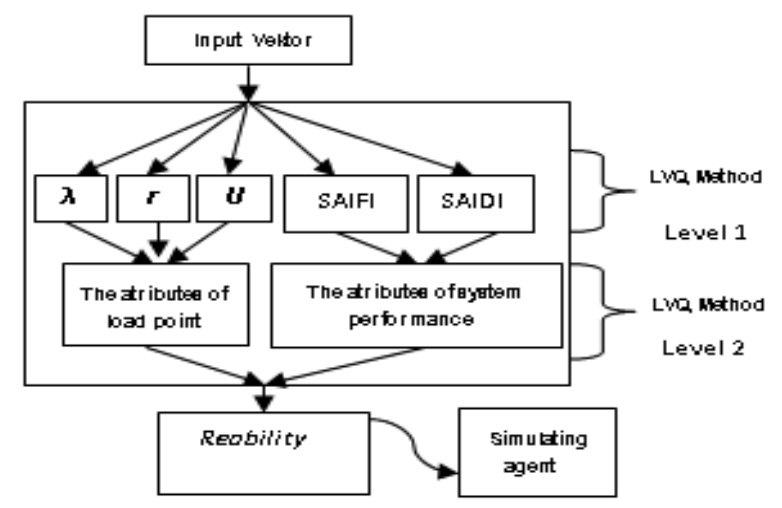

Figure-2. Flowchart of the study

A classification process is required to determine the reliability of the distribution system by the use of the attributes of load points and system performance index since the attributes of load point index has input vectors of $\lambda, r$, and $U$ and the attributes of system performance index has input vectors of SAIFI and SAIDI. Classification flowchart such as figure 2.

Classification of multiple attributes to determine the reliability of the distribution system using LVQ can be seen in detail in Figures 3, 4 and 5. The classification steps of the attributes of load point index and system performance index until the shortest distance from the input vectors to the class is obtained.

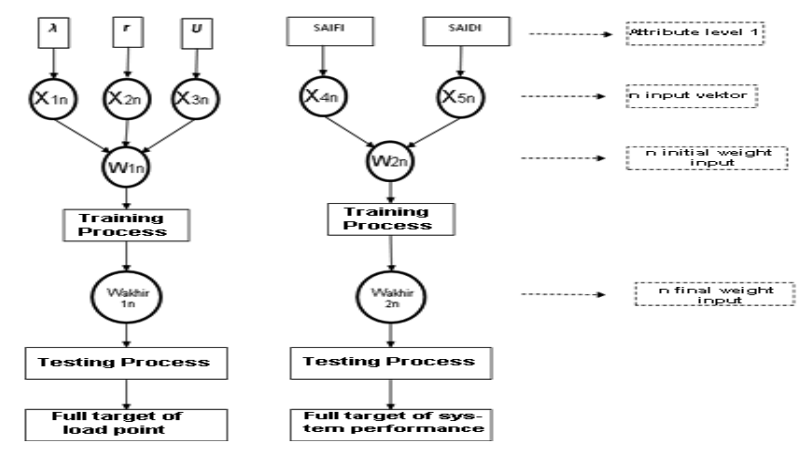

Figure-3. Flowchart of study step for attribute level 1

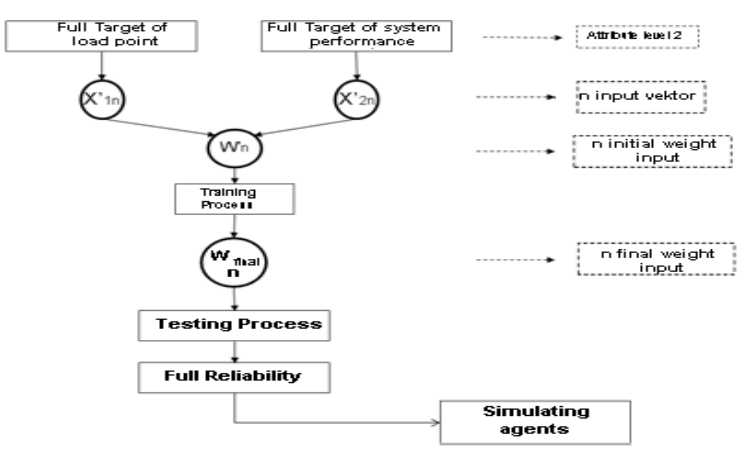

Figure-4. Flowchart of study step for attribute level
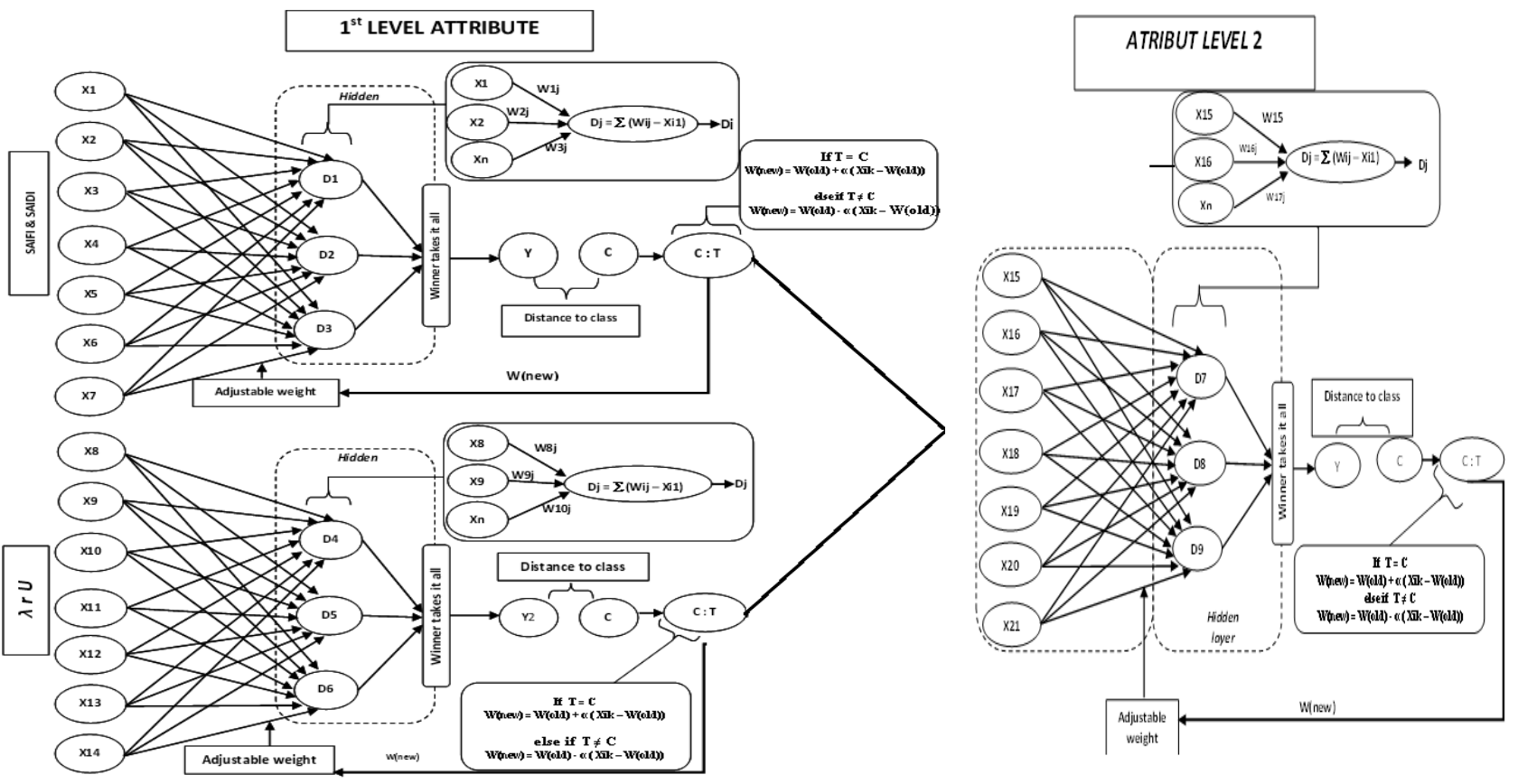

Figure-5. Process for attributes level 1 and attributes level 2 


\section{METHODOLOGY}

\section{Reliability Index}

Reliability index is an indicator of reliability expressed in a probability scale. Load point failure indices typically used include the frequency of failure $\lambda$ (failure/month), the average duration of an outage $r$ (h/failure) and the average annual outage time $U$ (h/year). The average value of the three basic load point indices for load point $j$ can be calculated from the (updown) operation history of the load point by using the following equation (Díaz and Márquez, (2014).

$\lambda=\frac{N_{j}}{\sum T_{u j}}$

$r_{j}=\frac{\sum T_{d j}}{N_{j}} \pi r^{2}$

$U_{j}=\frac{\sum T_{d j}}{\sum T_{u j}+\sum T_{d j}}$

$\sum T_{u j}=$ uptime for load point $j$

$\sum T_{d j}=$ downtime for load point $j$

$N_{j} \quad=$ number of failures during the simulation period for load point $j$

And based on Viktoria Neimane (Crespo and Benoit, 2007) to obtain the frequency of failure $\lambda$ (failure/year), the average duration of outage $r$ (h/failure) and the average annual outage time $U$ (h/year) as follows:

$\lambda_{s}=\lambda_{1}+\lambda_{2}+\cdots \cdot \lambda_{n}$

$r_{s}=\frac{\lambda_{1} \cdot r_{1}+\lambda_{2} \cdot r_{2}+\cdots \cdot+\lambda_{n} \cdot r_{n}}{\lambda_{1}+\lambda_{2}+\ldots+\lambda_{n}}$

$\cdot \cdot$

$\ddot{U_{s}}=\lambda_{s} \cdot r_{s}=\lambda_{1} \cdot r_{1}+\lambda_{2} \cdot r_{2}+\cdots+\lambda_{n} \cdot r_{n}$

System Average Interruption Frequency Index (SAIFI) is defined as the average number of failures per customer served by the system per unit of time (usually a year). (Fujiki and Kazuko, 2009).

SAIFI $=\frac{\sum \lambda k \cdot M k}{\sum M}$

$\lambda_{k}=$ outage rate of the component

$M_{k}=$ number of customers at load point $k$

$M=$ total customers in the distribution system System Average Interruption Duration Index (SAIDI) is defined as the average duration of failures for each consumer for one year. This index is determined by dividing the sum of continuous duration of failures for all customers during the specified period of time by the number of customers served during the year. The equation for SAIDI (average duration of interruption for each customer) can be seen in the following equation: (Fujiki and Kazuko, 2009).

$S A I D I=\frac{\sum U_{k} \cdot M_{k}}{\sum M}$

$U_{k}=$ component repair time

$M_{k}=$ number of customers at load point $k$

$M \quad=$ total customers in the distribution system The classification steps of the attributes of load point index and system performance index are described as follows: (Kate et. al., 2001; Robi, 2001; Olden et. al., 2004).

1. Determine the input vectors for each attribute;

2. Specify the initial weight randomly;

3. Determine the initial class as the target class in the training process of the input vectors.

4. During the learning process in the hidden layers, find the minimum distance to the input vectors of predetermined initial classes by using the Euclidean distance formula. $\mathrm{Dj}=\sum(\mathrm{Wij}-\mathrm{Xi})$

5. Once the minimum distance in the learning process has been obtained, the point is said to be the winner and the output, i.e., the minimum distance of the input vector to the target class is symbolized as the winner class.

6. Compare the winner class to the target class to find using the new weight by using the formula:

if

$\mathrm{T}=\mathrm{C}$

$\mathrm{W}($ new $)=\mathrm{W}($ old $)+\alpha(\mathrm{Xik}-\mathrm{W}($ old $))$

else if

$\mathrm{T} \neq \mathrm{C}$

$\mathrm{W}($ new $)=\mathrm{W}($ old $)-\alpha(\mathrm{Xik}-\mathrm{W}($ old $)$

Results obtained, i.e., the new weight $W$, are then used for trials.

Trials are continuously carried out with the term 'epoch' and will stop when the learning rate reaches a minimum value. The output of the process will be a minimum distance of the input vector to the class, in which the minimum distance data is simulated on the agent.

LVQ is a method that is based on an unsupervised learning algorithm. LVQ can also be used as a supervised vector quantizer since LVQ network has class points linked to the input vectors. (Kate et. al., 2001).

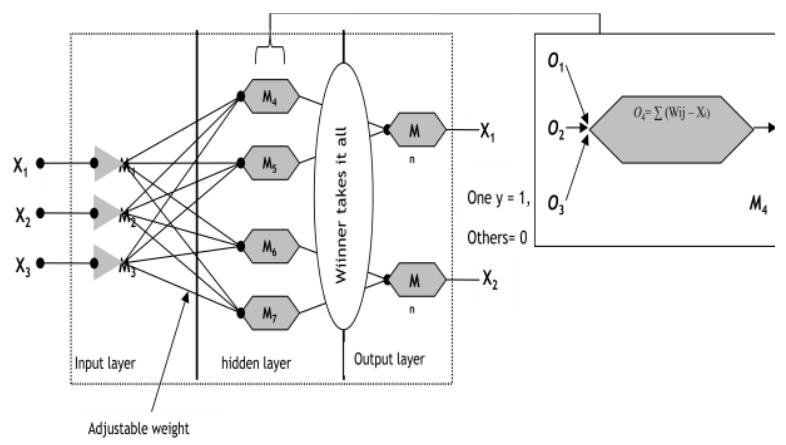

Figure-6. LVQ architecture: One hidden layer with kohonen neurons, adjustable weights between the input layer and the hidden layer (www.neural-forcasting.com)

The LVQ algorithm is as follows: (Sivanandam and Deepa, 2006)

1. Initialize weights and learning rate;

2. It will stop if it is incorrect, do steps 3-7;

3. For training input vector $\mathrm{x}$, do steps $4-5$

4. Calculate $j$ using the Euclidean distance formula

$D(j)=\sum(w i j-x i)^{2}$

find $\mathrm{j}$ when $\mathrm{D}(\mathrm{j})$ is at its minimum

5. Update $w j$ by follow the following requirements If $\mathrm{T}=\mathrm{Cj}$, then

$w j($ new $)=w j($ old $)+\alpha[x-w j($ old $)]$

If $\mathrm{T} \neq \mathrm{Cj}$, then

$w j($ new $)=w j($ old $)-\alpha[x-w j($ old $)]$

6. Calculate the error of the weighting values $\mathrm{e}(\mathrm{t}+1)=\|\mathrm{W}(\mathrm{t}+1)-\mathrm{W}(\mathrm{t})\|$

7. Reduce the learning rate

8. Perform trials for stop condition; the condition will stop when the iteration rate or learning rate reaches the smallest value. 


\section{FSM AND AGENT SCENARIOS}

FSM (Finite-State Machine) of the agent's simulated oil fuel distribution reliability is as figure 7. Agent scenarios based on the FSM in the simulation to determine the reliability of oil fuel distribution system is as follows:

1.Agents scan feeder (supply) 1 through feeder 7 to read the data of each feeder;

2. Subsequently, agents compare the data of the distance from the input vector to the class in all feeders;

3. Agents determine the shortest distance from the input vector to class 1 (class with the lowest possible interruption);

4. Then, agents block or mark green the feeder;

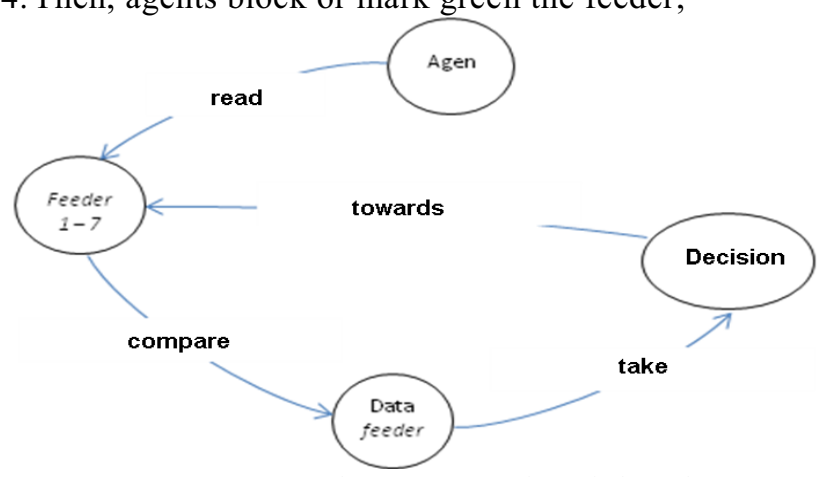

Figure-7. FSM of the agent's oil fuel distribution reliability

\section{TRIAL RESULTS}

Trial 1

1. Indication values of load points are derived from the total LP (load point) of each feeder on BUS 4;

2. Values of SAIFI and SAIDI are calculated using equations 7 and 8 based on data;

3. Class inputs for load point indications and SAIFI SAIDI are determined randomly as in Tables 1-2;

4. Total data $=7$

5. Number of the initial weight of each attribute $=3$

6. Number of class of each attribute $=3$

7. Max epoch $=10000000$

8. Based on case (A): disconnect - fuses - alternative supply - repair transformer.

Table-1. Data of load point and initial class indications

\begin{tabular}{|c|c|c|c|c|}
\hline Feeder & $\boldsymbol{\Lambda}$ & $\boldsymbol{r}$ & $\mathbf{U}$ & Class \\
\hline F1 & 1.343 & 157.25 & 30.14 & 1 \\
\hline F2 & 0.35 & 28.85 & 3.36 & 2 \\
\hline F3 & 1.299 & 161.55 & 30.01 & 3 \\
\hline F4 & 1.558 & 176.13 & 34.34 & 1 \\
\hline F5 & 0.344 & 29.19 & 3.36 & 2 \\
\hline F6 & 0.36 & 26.51 & 3.18 & 3 \\
\hline F7 & 1.313 & 160.07 & 30.01 & 1 \\
\hline
\end{tabular}

Table-2. Data of system performance and initial class indications for the case $\mathrm{A}$

\begin{tabular}{|c|c|c|c|}
\hline Feeder & SAIFI & SAIDI & Kelas \\
\hline F1 & 0.191 & 4.29 & 1 \\
\hline F2 & 0.117 & 1.12 & 2 \\
\hline F3 & 0.186 & 4.30 & 3 \\
\hline F4 & 0.195 & 4.30 & 1 \\
\hline F5 & 0.115 & 1.12 & 2 \\
\hline F6 & 0.120 & 1.06 & 3 \\
\hline F7 & 0.188 & 4.31 & 1 \\
\hline
\end{tabular}

Results obtained from the attribute level 1 for SAIFI and SAIDI (chain 1) ;

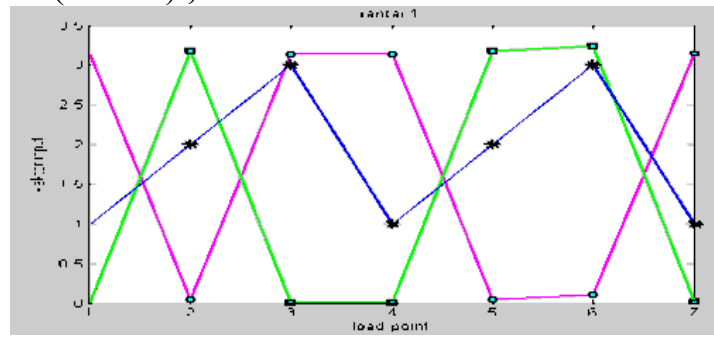

Figure-8. SAIFI and SAIDI input vector chart (case A)

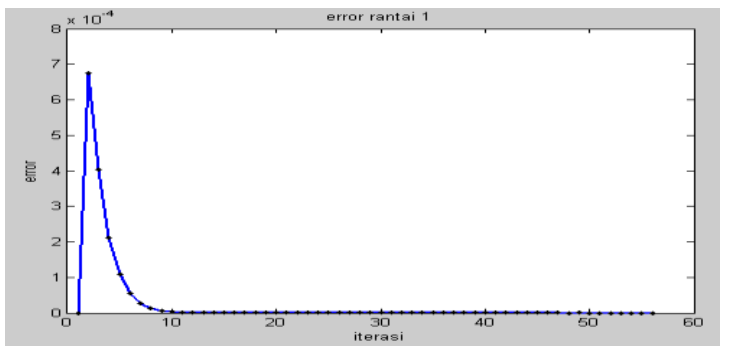

Figure-9. SAIFI and SAIDI input vector error chart (case A)

\begin{tabular}{|c|c|c|}
\hline \multicolumn{3}{|c|}{ Initial weight matrix } \\
\hline 0.1910 & 0.1170 & 0.1860 \\
\hline 4.2900 & 1.1200 & 4.3000 \\
\hline \multicolumn{3}{|c|}{ weight matrix after epochs to } \\
\hline 0.1925 & 0.1127 & 0.1762 \\
\hline & 1.1651 & 4. \\
\hline \multicolumn{3}{|c|}{ Distance after epochs to 56} \\
\hline 0.0087 & 3.1258 & 0.0154 \\
\hline 3.1 & 0.0 & 46 \\
\hline 0.00 & 3.1357 & 0.0 \\
\hline 0 & 3.1359 & 0.0 \\
\hline 3. & 0.0452 & 3.1746 \\
\hline 3.2 & 0.1054 & 3.2345 \\
\hline 0.0123 & 3.1458 & 0.0199 \\
\hline \multicolumn{3}{|c|}{ The initial class } \\
\hline 12 & 31 & 5 \\
\hline \multicolumn{3}{|c|}{ The bafter Training Class } \\
\hline 12 & 11 & 2 \\
\hline
\end{tabular}

Results obtained from the attribute level 1 for $\lambda, r$ and $U$ (chain 2);

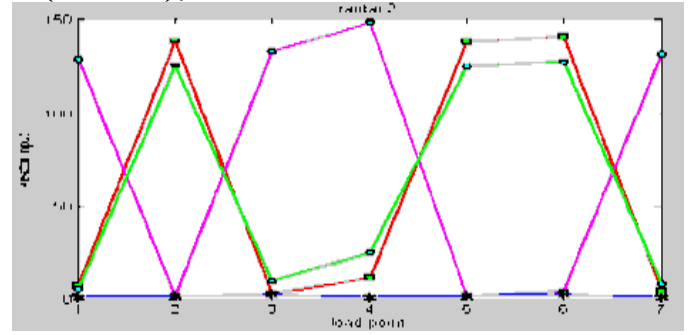

Figure-10. Input vector chart for $\lambda, r$ and $U$ (case A)

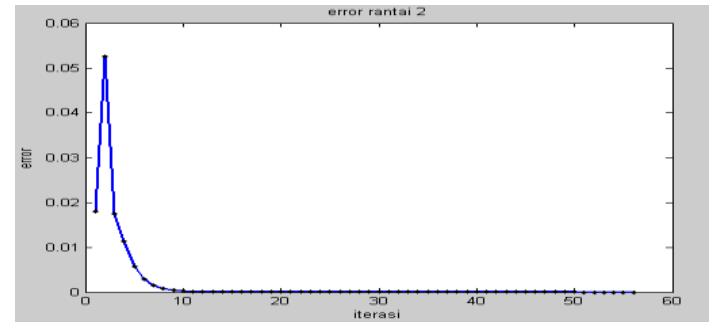

Figure-11. Error input vector chart for $\lambda, r$ and $U$ (case A) 
Simulation results Chain 2 (case A)

$* * * * * * * * * *$ Chain $2 * * * * * * * * * *$

Initial weight matrix

$\begin{array}{lll}1.3430 & 0.3500 & 1.2990\end{array}$

$\begin{array}{lll}157.2500 & 28.8500 & 161.5500\end{array}$

$\begin{array}{llll}30.1400 & 3.3600 & 30.0100\end{array}$

weight matrix after epochs to 56

$\begin{array}{lll}1.4179 & 0.3364 & 1.1122\end{array}$

$\begin{array}{lll}164.6319 & 30.9523 & 152.1007\end{array}$

$\begin{array}{lll}31.6555 & 3.4954 & 26.9819\end{array}$

Distance after epochs to 56

$\begin{array}{lll}7.5363 & 129.0816 & 6.0450\end{array}$

$\begin{array}{lll}138.7030 & 2.1067 \quad 125.4963\end{array}$

$\begin{array}{llll}3.4958 & 133.2656 & 9.9244\end{array}$

$\begin{array}{lll}11.8081 & 148.4232 & 25.1346\end{array}$

$\begin{array}{lll}138.3702 & 1.7675 & 125.1624\end{array}$

$\begin{array}{lll}141.0307 & 4.4535 & 127.8285\end{array}$

$\begin{array}{lll}4.8508 & 131.8156 \quad 8.5276\end{array}$

The initial class

$\begin{array}{lllllll}1 & 2 & 3 & 1 & 2 & 3 & 1\end{array}$

The bafter Training Class

$\begin{array}{lllllll}3 & 2 & 1 & 1 & 2 & 2 & 1\end{array}$

Results obtained from the attribute level 2 (chain 3 );

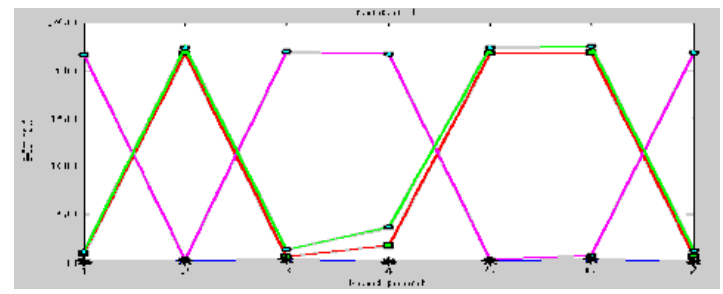

Figure-12. Input vector chart of the results of load point indications \& system performance indications (caseA)

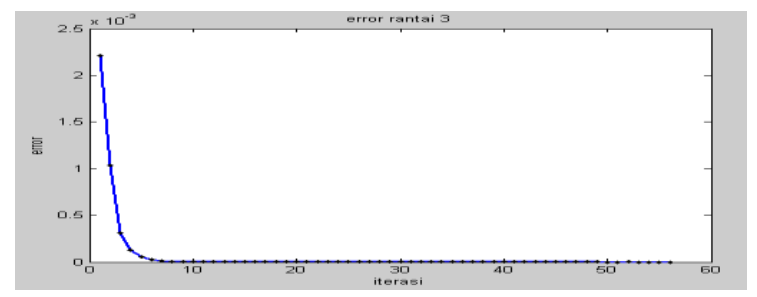

Figure-13. Input vector error chart of the results of load point indications \& system performance indications (case A)

Simulation results of all the input vectors (case A)

$* * * * * * * * * *$ Chain $3 * * * * * * * * * *$

Initial weight matrix

$\begin{array}{lll}0.0087 & 3.1794 & 0.0067\end{array}$

$\begin{array}{lll}3.1258 & 0.0453 & 3.1357\end{array}$

$\begin{array}{lll}0.0154 & 3.1746 & 0.0115\end{array}$

7.5363

$129.0816 \quad 2.1067$

$6.0450 \quad 125.4963$

weight matrix after epochs ke 56

$\begin{array}{lll}0.0093 & 3.1344 & 0.0089 \\ 3.1371 & 0.0000 & 3.1356 \\ 0.0203 & 3.1295 & 0.0066 \\ 8.6258 & 136.6172 & -1.4916 \\ 135.7772 & 0.0001 & 124.1710 \\ 12.6068 & 123.4060 & 0.7983 \\ \text { Distance after epochs ke 56 } & \\ \text { j class 1 } & \text { j class 2 } & \text { j class 2 } \\ 9.4379 & 217.0870 & 11.5389 \\ 218.0859 & 3.6281 & 223.9050 \\ \mathbf{6 . 3 1 0 4} & 219.9737 & 13.8156\end{array}$

\begin{tabular}{|c|c|c|}
\hline 18.0830 & 217.4703 & 36.8417 \\
\hline 217.9233 & 3.0476 & 223.6963 \\
\hline 219.2783 & 7.6748 & 225.4143 \\
\hline 6.8253 & 219.0071 & 12.5861 \\
\hline \multicolumn{3}{|c|}{ The initial class } \\
\hline 123 & 23 & \\
\hline \multicolumn{3}{|c|}{ The bafter Training Class } \\
\hline 12 & 22 & \\
\hline
\end{tabular}

\section{Analysis of Trial 1}

Trials for the attributes level 1 of chain 1 with SAIFI and SAIDI input vectors produced a feeder with the shortest distance from the input vector to class 1 or the class with high reliability. The feeder was feeder 4 which had a distance of the input vector to class 1 of 0.0029; in other words, feeder 4 had higher reliability as an oil fuel distribution system than other feeders. The next trials for the attributes level 1 of chain 2 for the input vectors $\lambda, r$ and $U$ produced feeder 3 as one that had high reliability as an oil fuel distribution system. It was due to the fact that feeder 3 had the shortest distance from the input vector to class 1 of 3.4958 .

Trials for chain 1 (SAIFI and SAIDI) and chain $2(\lambda, r$ and $\mathrm{U})$ were followed by classification of the attributes level 2 of chain 3 , or the attributes with the input vectors derived from classification of chains 1 and 2. Classification of the attributes level 2 of chain 3 was the last step of classification for case A, taking into account multiple attributes and using LVQ as the method of classification and obtained feeder 3 of 6.3104 as one with the shortest distance from the input vector to class 1 .

\section{Results of the Overall Trials}

Trials 1 to 6 for case A to case $F$ on feeder 1 to feeder 7 showed the Table 3 . Input vector distance data from all the attributes of all the cases to class 1 of each feeder. Multi-attribute classification was conducted on three classes:

Class $1=$ good, representing feeders with high system reliability

Class 2 moderate, representing feeders with medium system reliability

Class 3 = poor, representing feeders with low system reliability

Determination of the distribution system reliability as high, medium, low is shown only for feeders with the input vector distance for all cases approaching class 1 (high system reliability) as shown in figure 13. Reliability was also determined for attribute data consisting of load point indices and system performance indices. Furthermore, the data were simulated on the agents.

Table-3. Input vector distance of all feeders to class 1

\begin{tabular}{|c|l|l|l|l|l|l|}
\hline \multirow{2}{*}{$\begin{array}{c}\text { Feed } \\
\text { ers }\end{array}$} & \multicolumn{6}{|c|}{ Case } \\
\cline { 2 - 7 } & $\mathrm{A}$ & \multicolumn{1}{|c|}{$\mathrm{B}$} & \multicolumn{1}{|c|}{$\mathrm{C}$} & \multicolumn{1}{c|}{$\mathrm{D}$} & \multicolumn{1}{c|}{$\mathrm{E}$} & \multicolumn{1}{c|}{$\mathrm{F}$} \\
\hline 1 & 9.4379 & 9.6142 & 9.4381 & 9.4736 & 9.4379 & 10.0074 \\
\hline 2 & 218.0859 & 222.6989 & 218.1668 & 218.2161 & 218.0188 & 219.0970 \\
\hline 3 & 6.3104 & 6.6961 & 6.3168 & 6.3643 & 6.3104 & 7.3195 \\
\hline 4 & 18.0830 & 18.4926 & 18.0834 & 18.0994 & 18.0830 & 18.0878 \\
\hline 5 & 217.9233 & 222.5497 & 218.0080 & 218.0537 & 217.8560 & 218.9338 \\
\hline 6 & 219.2783 & 223.8759 & 219.3514 & 219.4085 & 219.2107 & 220.2855 \\
\hline 7 & 6.8253 & 7.1523 & 6.8277 & 6.8319 & 6.8253 & 6.8354 \\
\hline
\end{tabular}




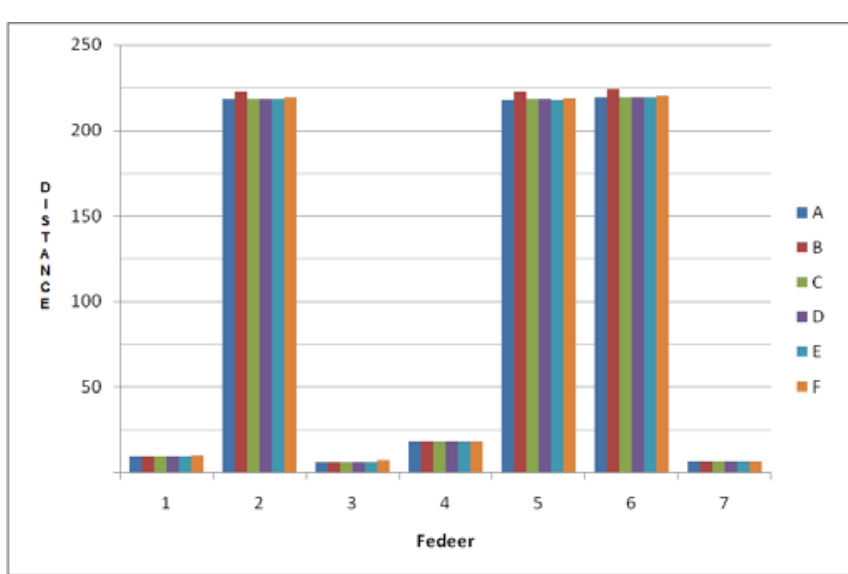

Figure-14. Chart of input vector distance of all cases to class 1

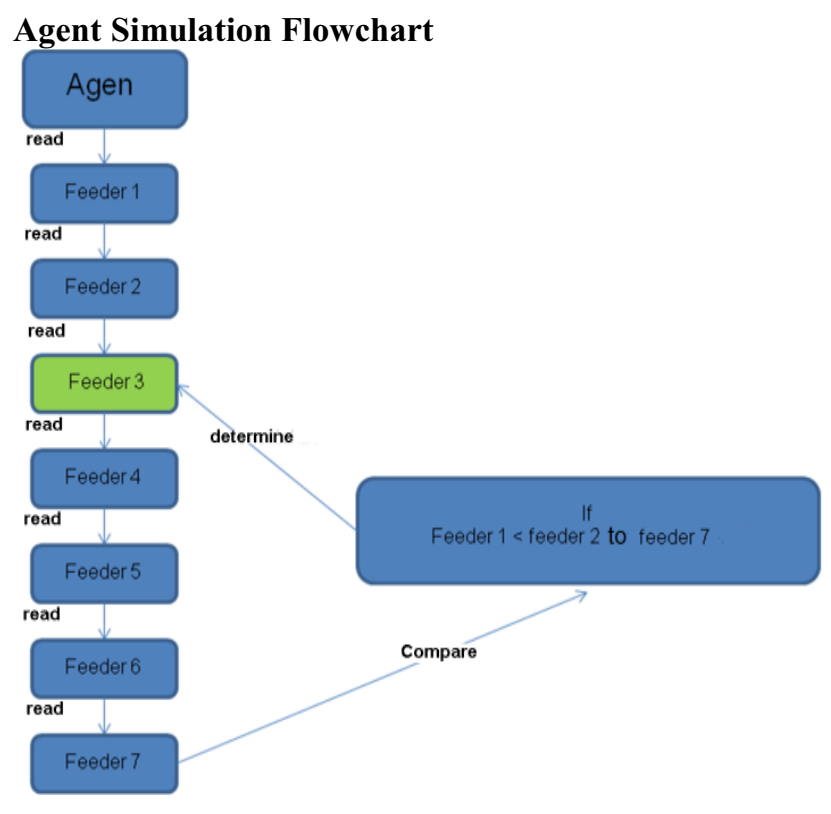

Figure-15. Agent simulation flowchart

\section{CONCLUSION}

Trials performed to determine the reliability of the oil fuel distribution system using LVQ (Learning Vector Quantization) showed that an oil fuel distribution system can be considered reliable when the interruption value was low. Utilization of more detailed attributes would be able to determine the reliability of the distribution system more accurately. This was due to the fact that oil fuel distribution system reliability is influenced by multiple aspects that can be used as attributes. The use of simulation in some problems is of paramount importance since it helps understand them visually. In particular, agent-based simulations for oil fuel distribution system reliability can visually help determine a reliable oil fuel distribution system. Future research should emphasize the determination of the initial weights of input vectors from LVQ method since initial weighting is essential to achieve classification accuracy. Future research should consider the use of Multi-Layer LVQ on each hidden layer capable of affecting the degree of accuracy in order to obtain better classification results.

\section{REFERENCES}

Ahmad, R., \& Kamaruddin, S. (2012). An overview of time-based and condition-based maintenance in industrial application. Computers \& Industrial Engineering, 63(1), 135-149.

Ardiansyah, F., Gunningham, N., \& Drahos, P. (2012). An environmental perspective on energy development in Indonesia. In Energy and non-traditional security (NTS) in Asia (pp. 89-117). Springer Berlin Heidelberg.

Crespo A. Márquez, Benoit Iung. 2007. A Estructured Approach for the Assessment of System Availability and Reliability Using Montecarlo Simulation. Journal of Quality in Maintenance Engineering. 13 (2): 125-136.

Dhillon, B.S. 2005. Reliability, Quality, and Safety for Engineers, CRC Press, USA

Díaz, V. G. P., \& Márquez, A. C. (2014). On the Assessment and Control. In After-sales Service of Engineering Industrial Assets (pp. 175-211). Springer International Publishing.

Fujiki Morii, Kazuko Kurahashi. 2009. Clustering Based on Multiple Criteria For LVQ and K-Means Algorithm, Journal of Advanced Computational Intelligence and Intelligent Informatics. 13: 360-370.

González Díaz, A. Crespo, P. Moreu, J. Gómez, C. Parra. 2009. Availability and reliability assessment of industrial complex systems: A practical view applied on a bioethanol plant simulation. Safety and Reliability for Managing Risk. Taylor \& Francis Group: 687-695.

Kate A. Smith, Frederick Woo, Vic Ciesielski and Remzi Ibrahim. 2001. Modeling the Relationship Between Problem Characteristics and Data Mining Algorithm Performance using Neural Networks. Intelligent Engineering Systems Through Artificial Neural Networks. 11: 356-362.

Olden, Julian D., Michael K. Joy, and Russell G. Death. 2004. An accurate comparison of methods for quantifying variable importance in artificial neural networks using simulated data. Modelling 178 (3): 389-397.

Portugal-Pereira, J., \& Esteban, M. (2014). Implications of paradigm shift in Japan's electricity security of supply: A multi-dimensional indicator assessment. Applied Energy, $123,424-434$.

Robi Polikar. 2001. Learn++: An Incremental Learning Algorithm for Supervised Neural Networks. IEEE Transaction on System, Man, and Cybertics Aplications and Reviews. 31: 497-508.,

Sivanandam S. N., Sumathi and Deepa. 2006. Introduction to Neural Networks Using Matlab 6.0. Tata McGraw-Hill Education.

Simões, M. G., Roche, R., Kyriakides, E., Miraoui, A., Blunier, B., McBee, K., and Ribeiro, P. (2011, September). Smart-grid technologies and progress in Europe and the USA. In Energy Conversion Congress and Exposition (ECCE), 2011 IEEE (pp. 383-390). IEEE. 